\title{
Adapting, Not Adopting: Barriers Affecting Teaching for Critical Thinking at Two Rwandan Universities
}

\author{
REBECCA SCHENDEL
}

\begin{abstract}
A recent study of student learning at three of Rwanda's most prestigious public universities has suggested that Rwandan students are not improving in their critical thinking ability during their time at university. This article reports on a series of faculty-level case studies, which were conducted at two of the participating institutions in order to investigate some of the reasons behind these results. Although educational practices likely to foster critical thinking skills are required elements of the undergraduate curriculum at both institutions, the case study analysis suggests that these practices are being fundamentally altered during implementation, because of a limited understanding of the rationale for pedagogical change and low levels of faculty motivation to implement more laborintensive teaching methods. The findings suggest that teaching and learning policies are only likely to be effective if accompanied by pedagogical training and support for ongoing faculty development.
\end{abstract}

In comparison with other institutions in the region, Rwanda's public universities have benefited from an unusually high level of rhetorical and financial support in recent years, largely because of the prominence of higher education as a core component of the country's national development strategy. As in many other countries around the world, much of Rwanda's support for its higher education institutions rests on an assumption that university graduates have the potential to contribute to a wide range of important industries, as a result of their ability to think critically about intractable social problems and to propose creative, evidence-based solutions. However, there is evidence challenging this assumption in the Rwandan context. A recent study conducted at three of Rwanda's most prestigious institutions indicated that Rwandan students are not improving significantly in their critical thinking ability during their time at university (Schendel 2015). In order to investigate some of the reasons behind this apparent lack of improvement, follow-on case studies were conducted at two of the institutions participating in the initial study. The resulting findings underscore the complexity of

I would like to acknowledge the contributions of my doctoral supervisors, Andy Tolmie and Moses Oketch; my research assistants, who helped enormously with logistics and translation throughout the study; and all of the study participants who volunteered their time to help with this research.

Received December 19, 2014; revised August 18, 2015, and October 24, 2015; accepted November 11, 2015; electronically published June 2, 2016

Comparative Education Review, vol. 60, no. 3.

(C) 2016 by the Comparative and International Education Society. All rights reserved.

0010-4086/2016/6003-0006\$10.00 
pedagogical change processes and highlight the crucial importance of faculty development as a key institutional priority, even within resource-limited settings.

This article presents the findings of these institutional case studies. It begins with a discussion of the study rationale and relevant theoretical background. The study methodology and results are then outlined. The article concludes by discussing the implications of the findings for higher education reform efforts in Rwanda and elsewhere in the region.

\section{Theoretical Background}

For decades, universities across sub-Saharan Africa struggled to maintain standards of academic quality, as international agencies and national governments reduced their higher education budgets in response to international pressure to prioritize funding for primary education (Salmi et al. 1994). However, in recent years, a new appreciation of the role of higher education in development has strengthened the justification for investment in universities across the continent (World Bank 2009). One of the primary assumptions motivating such investment is that higher education encourages the ability to think critically about problems. Critical thinking is considered crucial for participation in the global "knowledge economy," as it enables the adaptation of technology to local contexts (UNESCO 2009) and allows individuals to make determinations about the quality and reliability of the wide range of evidence now available online (Guile 2006). As industries change rapidly in order to address global demands, it has also become more difficult to predict which technical skills will be necessary throughout an individual's career. As a result, many universities are prioritizing fostering strategies and processes for lifelong learning, rather than focusing strictly on technical training for particular industries (Star and Hammer 2008). As a result of these converging factors, critical thinking is frequently cited as one of the most important outcomes of a contemporary university education.

Despite its widespread acceptance, the concept of "critical thinking" is one of the most debated constructs in education. There is little agreement over the definition of the term or how it might be taught or assessed. To some extent, the broad variation in definitions is a result of differences between the disciplines involved in discussions of critical thinking (e.g., psychology, philosophy, and sociology). However, even within the same discipline, the multifaceted nature of the concept inspires a number of theoretical debates, two of which are particularly contentious: whether critical thinking should be conceptualized as a skill (a position advocated by theorists such as Halpern 1996; Cottrell 2003; Bell 2005; Ennis 2009) or a disposition (suggested by Barnett and SRHE 1997; Bailin et al. 1999; Moseley 2005) and whether criti- 
cal thinking is a general or a domain-specific phenomenon (a debate exemplified by Moore 2004, 2011; Davies 2006).

As this study aimed to assess the development of critical thinking in Rwanda, it was deemed most appropriate to select a conceptualization of critical thinking in line with local representations of the term. Critical thinking is mentioned explicitly in a number of government documents, including in the national Economic Development and Poverty Reduction Strategy (MINEDUC 2010, 2) and the Education Sector Strategic Plan, where it is presented as a necessary "life skill" that allows individuals to "face the challenges" facing the nation. In order to meet these national objectives, the National Qualifications Framework lists "analysis, evaluation and critical skills" as core learning outcomes of any undergraduate program (MINEDUC $2007,3)$. These descriptions represent a conceptualization of critical thinking as a general ability that can be fostered within a particular academic discipline and then applied to a multitude of potential situations outside of the classroom. This definition resonates with Kuhn's (1999) theory of critical thinking development, which suggests individuals develop a number of "meta-knowing competencies" (i.e., cognitive and metacognitive skills and an increasingly sophisticated level of epistemological development) through the study of discrete academic subjects, which can then be applied to illstructured problems across domains. As cognition, metacognition, and epistemology have all been found to follow developmental trajectories, ${ }^{1}$ Kuhn suggests that critical thinking should also be viewed in developmental terms and that, as a result, one might expect critical thinking to improve through education.

Indeed, there is empirical evidence to suggest that critical thinking can be improved as a result of a university education (Pascarella and Terenzini 2005; Saavedra and Saavedra 2011). However, recent studies have also highlighted the lack of a consistent correlation between enrollment in university and development of critical thinking skills (Blaich and Wise 2010; Arum and Roksa 2011; Phan 2011). Although it appears that university education can encourage critical thinking, it is clear that this cannot be assumed, as the particular academic experiences provided to students within institutions have a substantial impact on their potential cognitive and epistemological development.

In the aggregate, the literature suggests that the approaches to teaching most likely to encourage critical thinking are those following a social constructivist philosophy, in which learning is conceptualized as an active process through which individuals work in collaboration with others to balance their preexisting knowledge with new information (Piaget 1975; Vygotsky et al.

\footnotetext{
${ }^{1}$ Piaget (1975); Vygotsky, Cole, and Luria (1978); King and Kitchener (1994); Kuhn (1995).
} 
1978). Often described as "learner-centered pedagogy," such approaches encourage students to question their preexisting assumptions and engage directly with a variety of different perspectives. By exposing students to new ideas and situations, teachers can stimulate the cognitive "conflicts" necessary for learning to occur, while also providing an appropriate level of support to prevent students from retreating from such conflicts (Bransford 1979). Examples of pedagogical methods in this tradition that encourage critical thinking include classroom discussions, class presentations, and both group and independent research projects (Tsui 2002; Kember and Leung 2005; Moon 2008). Assessment practices also play a crucial role. While multiple-choice and closed-answer examinations can encourage students to recount course content verbatim, open-ended assessments challenge students to demonstrate their own understanding of course content by applying their knowledge to new situations. This then provides the high level of challenge necessary for both cognitive and epistemological development (Entwistle and Entwistle 1997).

Although there is ample evidence to suggest that such approaches can help to encourage the development of critical thinking, it is also clear that the successful implementation of learner-centered pedagogy is challenging, as it relies on the active participation of both lecturers and students. Preexisting attitudes, motivations, and understandings of education are, therefore, key factors influencing the likely success or failure of such methods.

The pedagogical choices made by lecturers, as well as their behavior within the classroom, are influenced by their backgrounds (both disciplinary and personal) and by their beliefs about the purpose of education (Stark et al. 1990; Braxton et al. 1998; Tabulawa 2013). Tsui (2001) has identified three faculty attitudes that seem to have a particularly strong positive effect on student critical thinking ability: (1) instructor belief in the potential for students to improve their critical thinking skills, (2) enthusiasm for teaching and willingness to give extra effort to teaching practices, and (3) a perception of teaching as being a process of mutual learning, rather than the transmission of facts. However, many lecturers do not share these attitudes, because of their experiences (which may have reduced their belief in the potential of their students), their personal circumstances (which may reduce their motivation), or their preexisting orientations toward teaching (which necessarily influence their practice). Kember and Gow (1994) have argued that lecturers are likely to hold one of two teaching orientations: a "knowledge transmission" orientation or a "learning facilitation" orientation. Those holding a knowledge transmission orientation are likely to view teaching as a process through which experts transmit their knowledge to students; those with a learning facilitation orientation, however, see the role of the teacher as more of a coach or facilitator of learning. These orientations reflect what Tabulawa (2013) has called contrasting "pedagogical paradigms" - the 
learner-centered paradigm (which requires a learning facilitation orientation) and the teacher-centered paradigm (which is better suited to those with a knowledge transmission orientation) — and are likely to have a substantial impact on practice.

Student attitudes and motivations also play a crucial role. In addition to directly influencing critical thinking ability, academic experiences can have an indirect influence by affecting levels of student engagement. This is particularly important, given that the level of a student's engagement with his or her university education appears to be the single most important factor influencing the development of critical thinking ability (Astin 1984; Carini et al. 2006). Although students clearly enter university with preexisting attitudes and approaches to learning, which can affect the ways in which they engage with the learning process (Entwistle 1997), research has indicated that academic experiences also have a substantial impact - both positive and negative-on student engagement. Marton and Saljo's theory of learning approaches (1976) suggests that students tend to take either a "surface" approach to learning, in which they are focused on moving through the system and therefore apply the minimum effort required to progress from stage to stage, or a "deep" approach, in which they are motivated by a desire to understand the content of their education and therefore engage more meaningfully with the learning process. These approaches are clearly affected by students' preexisting attitudes and motivations. However, a number of pedagogical techniques can increase student motivation, leading to "deeper" approaches to learning, while other institutional and teaching norms can encourage increasingly "surface" approaches (Entwistle 1997; Biggs 2001). In fact, many of the academic experiences found to increase student engagement are the same as those found to have a significant impact on critical thinking ability (e.g., implementing active and collaborative learning methods, providing an appropriate level of academic challenge, and incorporating feedback to assist student learning). Enriching educational experiences, such as internships, field visits, and culminating final-year projects, have also been found to have a significant impact on student engagement at the university level (Kuh and DEEP 2005).

The development of critical thinking during university, therefore, appears to be affected both by the nature of the academic experiences encountered and by the interpersonal dynamics that occur within university classrooms. These factors, meanwhile, are affected by institutional policies and cultures, as well as by the background characteristics of both students and lecturers. To use the terminology of Astin's (1970) well-known InputEnvironment-Outcome model, this suggests that improvements in critical thinking are a function of the inputs into a university (e.g., background characteristics of students and lecturers), the particulars of the university environment, and the interactions that exist between the two. 


\section{Study Rationale}

The case studies described in this article comprised the second stage of a two-stage mixed-method study. During the first phase of the study, 220 firstand fourth-year students from three of Rwanda's public universities were randomly selected to complete an assessment of critical thinking, adapted for use in Rwanda. ${ }^{2}$ Cross-sectional analysis of the assessment results found no significant difference between the demonstrated critical thinking ability of the first-and fourth-year students in the sample (Schendel 2015), suggesting that students in Rwanda may not be improving in their critical thinking ability during their time at university. Additional quantitative analysis revealed no systematic relationship between individual student backgrounds (e.g., gender, socioeconomic status, parental education level, or secondary school type) and demonstrated critical thinking ability (Schendel 2015).

The existing literature offered one possible hypothesis to explain these results: that Rwandan university students are not improving substantially in their critical thinking ability because they have not been exposed to the kinds of academic experiences found to have a positive influence on the development of critical thinking skills. A second hypothesis - given that all of the existing empirical evidence linking academic experiences with critical thinking ability comes from non-African (largely high-income) contexts-was that the experiences found to positively affect critical thinking in other contexts do not have the same effect in Rwanda. Analysis of pedagogy at lower levels of education has acknowledged that cultural norms, values, and expectations around education can play a crucial role in the uptake (or rejection) of pedagogical reforms (Tabulawa 2013). However, there is limited literature considering the influence of culturally mediated values and attitudes on pedagogy within African universities. The second phase of the study investigated the potential influence of these institutional and cultural factors through a series of faculty case studies.

\section{Methodology}

The case studies were located within two of the participating universities: ${ }^{3}$ the National University of Rwanda (NUR) and the Kigali Institute

\footnotetext{
2 The assessment, based on the Collegiate Learning Assessment, took the form of a performance task in which respondents were given a real-world scenario and asked to make a decision about an illstructured problem, using evidence from a series of fictional documents. Space constraints prevent the inclusion of further information about the assessment format or the process used to adapt the instrument for use in Rwanda, but these can be found in Schendel and Tolmie (2016).

${ }^{3}$ As only 35 students from the third institution participated in the assessment phase of the study, it was not possible to draw any firm conclusions on the basis of the cross-sectional comparison from that institution. It was, therefore, not included in the case study phase.
} 
of Science and Technology (KIST). ${ }^{4}$ NUR and KIST have dramatically different institutional profiles. NUR was the first institution of higher learning in Rwanda. Established in 1963 just after independence, NUR is Rwanda's only comprehensive public institution. It is also the largest public university in Rwanda, enrolling over 11,000 undergraduate and postgraduate students. NUR is located in the city of Huye, which is approximately $150 \mathrm{~km}$ south of Kigali in Rwanda's Southern Province. NUR has seven faculties, two schools, and a number of research centers, and it employs approximately 500 academic staff. In contrast, KIST was established quite recently (in 1997) and is focused exclusively on applied sciences and engineering (KIST Directorate of Planning and Development 2007). KIST is located in Kigali, the capital of Rwanda. KIST has three academic faculties and employs approximately 240 academic staff. In 2012, there were 2,446 full-time undergraduate students enrolled at KIST.

Given the differences in size and disciplinary scope between the two institutions, a multiple embedded case design was pursued (Yin 2009). Students in Rwanda enroll in a particular faculty and have no substantive interaction with other faculties at their institution. Lecturers also tend to interact predominantly with others in their faculty. The decision was therefore made to focus on individual faculties as the unit of analysis.

Although all three of the KIST faculties could reasonably be included in the study, it was not possible to include all seven of the NUR faculties and still maintain balance within the sample. As a result, three NUR faculties were purposively selected for inclusion in the study. Two (the faculty of science [FOS] and the faculty of applied sciences [FAS]) were chosen because of their disciplinary similarity to the faculty of engineering (FOE) and FAS at KIST. The faculty of economics and management (FEM) was selected as the final case, as it was deemed important to include at least one social science discipline in the sample, and the FEM has the largest student population of any faculty at NUR. The case study phase therefore focused on six faculty cases: FOS, FAS, and FEM at NUR and FOE, FAS, and the faculty of architecture and environmental design (FAED) at KIST. Although not exhaustive in terms of its disciplinary coverage, the faculty sample represented a range of applied subjects, all of which emphasize inquiry and feature prominently in Rwanda's national development strategy (Republic of Rwanda MINECOFIN 2000).

All data were collected between September and December 2012. The study incorporated three primary data collection methods: focus groups with students, individual interviews with students, and individual interviews with

\footnotetext{
${ }^{4}$ In 2013, Rwanda's public universities were redesignated as constituent colleges of the consolidated University of Rwanda. The individual institutions outlined in this article are therefore no longer independent entities. However, the names and descriptions of the former institutions have been retained throughout the article to reflect circumstances at the time of data collection and analysis.
} 
faculty members and administrators. Relevant policy documents and marketing materials were also reviewed. Individual student interviews were conducted with "positive outliers" (i.e., students who had performed particularly well on the critical thinking assessment), in order to identify possible experiences that might be positively associated with strong critical thinking skills. In contrast, the student focus groups included a range of participants, in terms of their performance on the critical thinking assessment, and emphasized student attitudes toward university and academic experiences within the various faculties under investigation. Focus groups were selected as an appropriate methodology for this objective, as they allowed for the consideration of a wide diversity of student experiences, while also providing the possibility of immediate follow-up and clarification of unexpected information (Marshall and Rossman 2006). It was also anticipated that group interviews might be less intimidating for some participants, particularly those less comfortable in English or French. As one important area of inquiry was students' perceptions of the knowledge and skills acquired during university, participation was restricted to those students who had been fourth-years at the time of the assessment. In total, 10 individual student interviews (five from each of the participating institutions) and six student focus groups (three at each participating institution) were conducted. ${ }^{5}$ Faculty and administrator interviews, meanwhile, explored pedagogical practices within the participating faculties, attitudes toward teaching, and academic policies. At each institution, interviews were held with nine faculty members (representing both genders and a range of academic disciplines and ranks) and one senior administrator.

Interviews were held in English, French, or Kinyarwanda, depending on participant preference, and recorded with participant consent. After the interviews, all French and English content was transcribed by the author, while any Kinyarwanda content was transcribed, translated, and checked by a team of nine Rwandan university students assisting with the study.

Analysis of the case study data was completed in two phases: first within and then across the two institutions. Before data collection, an initial code list was generated, based on the key concepts discussed in the existing literature. An analytical strategy with both inductive and deductive elements was then employed, in which data were examined both for connections to the existing literature and for new emergent themes (as suggested by Dowling and Brown 2010).

Within each institution, this analytical process was iterative, with ongoing analysis informing the collection of new data. During analysis, matrices were used to display emerging themes and monitor whether sufficient data had

\footnotetext{
${ }^{5}$ Fifteen students from KIST and 11 students from NUR participated in the six focus groups. Both the individual and the group interviews included male and female students from all six participating faculties.
} 
been collected from each faculty. Network diagrams were constructed to describe the major processes that appeared to be occurring within the selected faculties, and brief narratives were written to accompany the diagrams and begin the process of building potential explanations (Yin 2009). The diagrams also helped to identify potential intervening variables that may not have been considered during initial coding (Miles and Huberman 1994). At the end of data collection at each institution, an overarching network diagram, representing all of the major explanatory themes, was constructed and shared with those research assistants who had attended the institution under investigation, in order to solicit feedback on the emerging explanations and to generate alternative perspectives on the data.

Cross-institution matrices were then used to compare and contrast data from the six faculties, in terms of the relevant dimensions suggested by the existing literature. The data were then regrouped according to emerging explanations for any observed differences and similarities, and a series of models was created to represent the different processes that seemed to be occurring within each faculty. As at the institutional stage, narratives were written to accompany the models and outline initial explanations. At the end of analysis, a final validation meeting was held with the full research team, during which the research assistants were asked to provide feedback and suggest any alternative explanations that might have been missed.

Throughout analysis, findings were continuously examined for their credibility and trustworthiness, through the use of verification techniques advocated by Miles and Huberman (1994) and Yin (2009). NVivo software was used to assist with both data management and analysis.

\section{Adapting Instead of Adopting}

An initial review of institutional policies affecting the six case study faculties revealed that many of the academic experiences found to have a positive impact on critical thinking have, in fact, been required elements of the undergraduate curriculum at both KIST and NUR since the recent implementation of new teaching and learning policies at the two institutions. Interviews with both students and faculty members confirmed that these requirements are being followed. Students reported participating regularly in group assignments and class discussions, while faculty members claimed to frequently use site visits, guest lecturers, and laboratory work. All KIST and NUR students complete an internship and a final culminating project, and final examinations at both institutions are required to include at least one open-ended, application-based question in which students synthesize their learning by proposing a solution to a complex problem. It therefore quickly became apparent that a strict interpretation of the first hypothesis - that students in Rwanda are simply not exposed to such pedagogical approaches- 
was not a valid representation of the academic environment at either of the participating institutions. However, the evidence from the case studies did suggest that limited exposure to learner-centered pedagogy might be driving the assessment results in a different way, as the interviews revealed that, in five of the six participating faculties, practices found to positively influence critical thinking ability in other contexts are being fundamentally adapted during implementation. ${ }^{6}$

A clear example of this adaptation process can be found in the domain of collaborative learning. Group work is required by all undergraduate programs at KIST and NUR. However, participants indicated that group assignments are typically quite small in scope and can, therefore, feasibly be completed by one or two people. Faculty and student participants at both institutions acknowledged that the majority of students do not participate in group assignments. Rather, one or two students generally complete the assignment for a group, while other group members contribute money for photocopying fees and add their names to the final report. Group projects typically include a short written assignment and a class presentation. Although some faculty members require all members of a group to participate in the presentation, many allow groups to select their own presenters. Collaborative learning has been found to influence critical thinking when the collaborative element introduces students to alternating viewpoints and perspectives. The group projects currently implemented at KIST and NUR are unlikely to have such an effect.

Similarly, class discussions at the two institutions, although commonplace, are unlikely to offer the benefits outlined in the literature. Participants generally described class discussions as being an opportunity for students to ask questions and clarify concepts, rather than a forum for exploring new ideas or differing perspectives. One graduate of the KIST FOE, for example, defined class discussions as a time when "each [student] brings his ideas, then we choose those ones we all agree with," while another explained that discussions allow faculty members to clarify difficult concepts: "A lecturer can first - he can ask a question and try to capture the points of views of many people.... We give different responses. And the teacher decides which one is true. Which are false" (graduate of FOE, KIST). NUR participants described classroom discussions in similar terms. For example, one faculty participant defined class discussions as follows: "When I'm teaching maybe three hours, I teach for like two hours and 15 minutes. Then we have 45 minutes of different questions on the overall coverage of what we did. If there are queries there ... If there are things that they did not understand well. Then we clear

\footnotetext{
${ }^{6}$ Space constraints prevent analysis of the outlying case within this article. The interested reader is referred to Schendel (2013).
} 
them up before we close on the chapter" (junior faculty member, Department of Economics, FEM, NUR).

Although referred to as "discussions," there is little evidence that such practices involve any debate or dialogue between students. As discussions focused on getting the "correct answer" do not encourage students to question their own understanding of a concept (Dewey 1933; Kuhn 2005), such practices are unlikely to have a positive impact on critical thinking skills. The benefits of discussion are likely to be further reduced by low levels of English language ability at Rwandan universities, as student participants indicated that student language ability often prevents active participation in class discussions: "Normally [we don't have discussions].... For students who studied in the Francophone system, it's very difficult to speak in English. So, [discussions] could waste a lot of time" (graduate of FEM, NUR; initially expressed in French). ${ }^{7}$ "Active" teaching methods, such as laboratory work, also differ in practice from what is advocated in the literature. At KIST, students typically follow a prescribed laboratory protocol, rather than generating their own experiments. At the end of a given experiment, students write a summary laboratory report, either individually or in groups. In one interview, a tutorial assistant from the FAS explained that plagiarism is a common issue with laboratory reports, as students copy one another's results and conclusions. Students at both institutions indicated that students are generally prevented from using expensive laboratory equipment. If the use of equipment is a necessary component of an experiment, lab technicians are asked to conduct the experiment while the students observe. A number of faculty participants also noted that the university timetable does not allow for lengthy experiments. Some choose to address this issue by organizing one or two laboratories during the semester, instead of regularly including laboratory work throughout the term. A lack of basic materials, such as reagents, and high student-to-faculty ratios also limit the inclusion of laboratory work in the curriculum. Although students undoubtedly benefit from occasionally observing experiments, it is unlikely that such methods stimulate much student engagement or foster skills of inquiry.

Although studies have indicated that a culminating final project can help students to synthesize and integrate the information that they have learned during their time at university (Kuh and DEEP 2005; Bok 2006), the final projects completed at KIST and NUR are unlikely to offer such benefits. Students are rarely assessed through written assignments before the final project, and, aside from one module on research methodology, little guidance is provided to help students prepare for the experience. The high student-to-

\footnotetext{
${ }^{7}$ For the majority of Rwanda's colonial and postcolonial history, French was the language of instruction. After the genocide, a bilingual system was introduced (French and English). However, in 2010, French was abolished, leaving English as the only official language of instruction at secondary and tertiary levels.
} 
faculty ratio in most departments also prevents any possibility of meaningful supervisory relationships, as faculty members can be responsible for supervising up to 50 student projects each year. However, despite the lack of preparation for such an undertaking, most programs require a final written project of at least 20,000 words. The limited preparation and supervision, combined with low levels of English, often results in blatant plagiarism, a fact acknowledged by student and faculty participants alike. Participants indicated that a recent decision to eliminate government scholarship funding for final projects has exacerbated the problem. Projects requiring transportation or the provision of incentives to study participants are no longer possible given these financial constraints, nor are projects based on laboratory experiments, as they typically require the use of expensive private laboratories, because of restrictions on student use of university laboratory facilities. As a result, students are increasingly opting to copy data from other sources, instead of collecting them themselves. Such circumstances limit the potential of the final project to foster the development of student critical thinking skills.

The requirement that every final examination include at least one openended synthesis question is also unlikely to have much of an impact on cognitive development. Participants indicated that the norm at both institutions is for examinations to include only one synthesis-type question per assessment. As a result, it is mathematically possible for students who have received good marks throughout the term to avoid the open-ended question altogether and still pass the examination and the module. It appears likely that many students at KIST and NUR would make such a choice, as a number of participants mentioned that students often calculate the minimum marks required to pass any given module and adjust their study strategies accordingly. Furthermore, students are not given any opportunity to practice answering similar questions during the semester, given the lack of writing assignments and the closed nature of most class discussions. Synthesis-type examination questions can be helpful for developing critical thinking skills, provided students are given sufficient feedback and opportunities to practice during the semester. However, given the apparent lack of such support within most of the participating faculties, the inclusion of one synthesis-type question per examination is unlikely to have a positive effect on student critical thinking skills.

Although both KIST and NUR have attempted to promote the kinds of academic experiences likely to foster the development of critical thinking skills in their student populations, the evidence suggests that these centralized academic policies have not resulted in a fundamental change in pedagogical practice at either institution. Rather than adopting new teaching methods as a result of the policies, faculty members instead seem to be adapting them to suit their preexisting teaching practices. 


\section{Exploring Lecturer Perceptions and Motivations}

Further analysis of the case study data suggests two primary reasons for this adaptation process: limited understanding of the proposed pedagogical changes and limited motivation to implement labor-intensive teaching methods.

\section{Faculty Comprehension of Proposed Innovations}

When asked about their own experiences at university, most of the faculty participants described traditional teaching structures in which classrooms were organized around the transmission of knowledge from the lecturer to the student. Very few had any personal experience with more active or collaborative teaching methods. As one participant explained: "Yeah. It was quite hard for ... people to [change].... [It's a] problem of understanding this student-centered learning, etc. Because we used to teach in the ancient system. The lecturer used to be the king of the class - come and teach on the board, surprise the students, you know?" (senior administrator, NUR). Having never been personally exposed to more student-centered approaches, it is likely that traditional methods are synonymous with the concept of "education" in the minds of many instructors in Rwanda. Indeed, most of the faculty participants in the study indicated that they view education as being a process of transmitting information and knowledge to students. Most stated that student comprehension of course content was their primary teaching objective and described the purpose of assessment as being the objective measurement of student retention of information. In other words, the data suggest that Rwandan lecturers tend to have a "knowledge transmission" orientation toward teaching (Kember and Gow 1994).

Furthermore, it appears that the teaching and learning policies requiring a more learner-centered pedagogy were implemented quite rapidly at both of the participating institutions. The speed of the reforms seems to have prevented in-depth discussion of the new policies with the university faculty. As a senior administrator involved in the reform explained: "In 2007, we started with the new way of teaching. ... I was ... happy, because I knew the ... system, since I came from Europe in 1994.... I'd watched debates ... in various universities, in various countries, etc.... Here, [we] could prevent against those debates, which would be a waste of time. So, we forced the things to start in 2007" (senior administrator, NUR). Although participants indicated that workshops on pedagogy were offered to staff members at the time of the reforms, they appear to have been standalone events, rather than a sustained source of support for instructors. In addition to the unlikely longterm impact of one-off training sessions, the lack of continuous training opportunities has prevented newer members of staff (who are equally likely to have had limited experience with learner-centered methods) from re- 
ceiving the benefit of any explanation of the rationale behind the policies. As a senior administrator at KIST explained: "Initially, you find, because people were not quite understanding, there was a bit of - I won't call it resistance-but not knowing, not understanding what it was all about. [The] workshops, clearly, helped ... some of them. ... The disadvantage would be if someone was there and then start going away again, and the new ones come. We have not yet dealt with these new ones coming."

Tabulawa (2013) has argued that the "paradigms" of teacher- and learner-centered pedagogy rest on fundamentally different epistemological foundations. As a result, simply requiring lecturers to change their practice is likely to be insufficient, as instructors must first understand both the purpose of the innovation and the means through which they can effectively accomplish the desired outcomes (de Corte 2000; Green and Sakamoto 2001). Baxter Magolda (1999) agrees, arguing that, without explicit training and support, lecturers are likely to adapt new academic policies to match their preexisting understanding of the nature of education and the practice of teaching. It is this process that appears to be occurring in Rwandan classrooms. Requiring instructors to incorporate classroom discussions into their teaching in order to foster abstract thinking skills, for example, assumes that instructors can see how such a pedagogical approach supports student cognitive development. However, without prior exposure to open-ended classroom discussions, instructors with knowledge transmission orientations are likely to construct classroom discussions to support their focus on transmitting course content to students (as, indeed, appears to be occurring in classrooms across KIST and NUR). From a transmission perspective, it is logical to use discussions to help students to clarify important concepts. In contrast, the kind of classroom discussion likely to encourage critical thinking skills requires a completely different conceptualization of what it means to be a teacher. Instead of the expert transmitting knowledge, the instructor in such a discussion needs to assume the role of facilitator, creating an environment supportive of student exploration of a range of different perspectives on a given topic or issue. Similarly, open-ended synthesis-type assessment questions are likely to be viewed as a means of evaluating student comprehension of course notes (as appears to be the case for faculty participants in this study), unless faculty members view assessment as a formative tool in the learning environment (Entwistle and Entwistle 1997).

In other words, successful implementation of the kinds of pedagogical practices outlined in the literature-and, indeed, in the teaching and learning policies at KIST and NUR - requires a shift from a "knowledge transmission" to a "learning facilitation" orientation toward teaching. However, it is unrealistic to assume that such a fundamental epistemological shift can occur simply through the administration of a centralized policy. Explicit instruction and sustained support for faculty development is crucial, partic- 
ularly given the psychological hurdles that can hinder the adoption of new teaching methods. It can be threatening to question the techniques used during one's own education, as recognizing limitations raises questions about one's own learning. Much as students need to be supported when facing disorienting concepts, lecturers are likely to require support when challenging deeply rooted perceptions about their profession (Baxter Magolda 1999). Lecturers are also likely to need guidance to help them execute new teaching methods. Many of the pedagogical approaches found to support student critical thinking ability require careful planning and facilitation. Group projects, for example, are most effective when the groups are carefully constructed (Arum and Roksa 2011), while successful class discussions require thoughtful facilitation by the instructor, particularly when students are unfamiliar with collaborative techniques or when educational practice challenges traditional notions of authority (as discussed in Tikly and DFID 2003). Indeed, in addition to affecting teaching orientations, past academic experiences result in deeply engrained perceptions of education within students. As most Rwandan secondary schools continue to use traditional methods of teaching, students entering university in Rwanda are unaccustomed to seeking out new perspectives or viewing their peers as reliable sources of information. Rather, students expect to receive knowledge directly from their instructors (Mbabazi Bamwesiga et al. 2012). Pedagogical methods that challenge such engrained understandings of education can cause feelings of disorientation and resentment in students (Moon 2008), so instructors need to be equipped with the tools necessary to effectively support students through the more challenging aspects of the learning process. The apparent lack of pedagogical training or support for faculty development at KIST and NUR is, therefore, likely to have limited the ability of lecturers to fully understandand successfully implement - the kinds of pedagogical innovations espoused by institutional policies on teaching and learning.

\section{The Issue of Motivation}

For at least some instructors, limited understanding of the rationale behind the teaching and learning policies is compounded by a lack of motivation. All of the pedagogical practices found to encourage the development of critical thinking skills require significantly more time and effort from instructors than a traditional lecture-based approach (Tsui 2002; Moon 2008). Most require a substantial amount of preparation, as well as the active involvement of the instructor during class. The effective implementation of such practices is therefore dependent on the motivation of faculty members. However, the evidence suggests that faculty morale is low at both KIST and NUR. Although many faculty participants in the study demonstrated a clear passion for teaching and a high level of motivation to ensure student success, others indicated that there would need to be a significant change in their 
circumstances in order for them to contribute the effort required to effectively implement any labor-intensive pedagogical innovations.

At both institutions, participants indicated that the primary source of low faculty morale is the poor salaries provided to lecturing staff at Rwanda's public universities. The incentive structures at the two institutions also seem to affect faculty motivation to invest time and energy in teaching. Similar to most international research universities, promotions and pay rises at both KIST and NUR are largely determined by research productivity; teaching does not figure in promotion decisions at either institution. In addition to minimizing the importance of teaching, the incentive structure at KIST contributes to low faculty morale, as, despite the focus on research within the incentive structure, there is almost no research culture on the KIST campus. Faculty members cannot access funding for research projects, so the quality of research produced tends to be quite low. As a result, very few KIST faculty members are eligible for promotion. A number of participants explained that lecturers used to cope with the limited opportunities for progression by taking on additional work outside the university. However, in an effort to reduce lecturer absenteeism, KIST recently banned the pursuit of outside employment. This decision has generated significant resentment, as lecturers perceive that the policy has taken away their individual agency and ability to improve their standard of living. Morale is higher at NUR, as there is a more vibrant research culture; funding is available for faculty research projects, and the number of publications is rising. Unlike at KIST, lecturers at NUR are allowed to seek external employment, and many do have additional teaching or consultancy responsibilities at other institutions. Although this appears to be positive for morale, the pursuit of supplementary income can have a detrimental effect on the learning environment. As the vast majority of supplementary work is located outside of Huye, NUR lecturers spend a significant amount of time away from campus. Student and faculty participants alike noted that it is common practice for faculty members to arrange their lectures around these other commitments, resulting in situations in which students are expected to follow all of the lectures for a given module within the space of a few days. This reduces the likelihood that lecturers will engage in timeconsuming activities, such as class discussions or laboratories, and it limits the ability of students to complete reading and other independent work outside of contact hours. Lecturer absenteeism also reduces the time available for student supervision of final projects.

In addition to salary-based concerns, participants expressed frustrations with changing conditions on their campuses. Student enrollment is increasing dramatically every year, particularly at NUR. However, departments do not have the funding to hire more staff or to improve teaching facilities. As a result, lecturers have to work within extremely challenging infrastructural constraints. One participant described having to teach over 200 students in 
a classroom with only 100 chairs. Others mentioned feeling overwhelmed and pressured by the constantly changing policy environment in Rwanda. Since 2008, the public universities have changed their language of instruction, their admissions practices, their academic calendar, and their curricular structure. Faculty participants who have worked within the system for a long time feel that they have been asked to change every aspect of their practice without any compensation or support from the government or their institution. This has further contributed to declining morale.

These conditions have resulted in low levels of motivation within many of the academic departments at KIST and NUR, which may be limiting lecturers' willingness to contribute the effort required to change their pedagogical practice. Indeed, the data suggest that many faculty members are choosing to avoid the most labor-intensive elements of the teaching and learning policies. To take one example, lecturers can claim they are following university requirements as long as they incorporate some group work into their module content. Thoughtfully structuring group projects is a timeconsuming exercise. However, the kinds of group projects described by the study participants require minimal effort on the part of the instructor. As it is this latter form of "collaborative learning" that is being implemented within most of the participating faculties, it seems that low levels of faculty motivation may also be contributing to the adaptation process occurring at KIST and NUR.

\section{Conclusion and Implications}

The results of the case study analysis suggest that neither of the original hypotheses offer a sufficient explanation for the apparent lack of improvement in critical thinking ability identified within KIST and NUR. The limited progress in critical thinking is clearly not the result of a simple lack of exposure to particular pedagogical methods, as all of the methods advocated by the literature are explicitly required by centralized policies on teaching and learning at both institutions. There is also insufficient evidence to support the second hypothesis - that learner-centered approaches cannot have a positive effect on students in Rwanda. What the case study results indicate instead is that such methods are unlikely to be successfully implemented unless due consideration is given to lecturers' values and attitudes toward teaching. Existing theoretical understandings of how critical thinking can be developed at the university level may be relevant for use in contexts such as Rwanda. However, the findings from this study suggest that further analysis is needed of attempts to foster critical thinking within diverse cultural contexts in order to extend our understanding of how student-centered approaches are implemented (or resisted) by lecturers and students from different cultural backgrounds. 
Although this article reports on the results of a small-scale study of two universities in Rwanda, these findings offer an important perspective on ongoing attempts to improve university pedagogy, both in Rwanda and elsewhere. Most importantly, the findings suggest that centralized academic policies, although an important first step toward institutional change, are unlikely to result in the widespread adoption of new techniques. As universities around the world grapple with the challenge of how best to improve the critical thinking skills of their students, it is crucial that experiences such as those documented in this article serve as a reminder that university lecturers are unlikely to modify their teaching methods unless they understand the rationale behind the use of particular methods and perceive the need for change. This, in turn, requires an understanding of how lecturers see themselves and their profession. Unless these psychological and philosophical influences on teaching are taken seriously, pedagogical reforms are unlikely to result in significant change, as the tendency will be for faculty members to behave as they have done at NUR and KIST: by subconsciously adapting policies to match their preexisting teaching orientations and pedagogical preferences.

Sustained and substantial faculty development programming, therefore, appears to be a crucial component of any attempt at pedagogical reform. However, it is important to acknowledge that pedagogical training at the university level is not without its challenges. The suggestion that lecturers need to improve their teaching practice can be met with resistance, particularly by more experienced members of academic staff. Incorporating recognition of teaching excellence into university incentive structures can address some of these motivational aspects. However, this is an unlikely step for many institutions, given that the pressures of global competition tend to encourage universities to give higher priority to other more internationally valued indicators, such as research output and student completion rates. The cost of regular pedagogical training can also be quite prohibitive, particularly for universities in resource-constrained environments. Indeed, the administrators participating in this study indicated that, although they recognize that academic quality must be improved, they are frustrated in their ability to affect change, given their reliance on unpredictable levels of government support. Although standalone training and workshops are highly unlikely to affect systemic pedagogical change, they are often the most feasible option for resource-constrained institutions. More reliable access to funding could help institutions to better address academic quality concerns on their campuses, but public funding for higher education has reduced, rather than increased, in recent years. This suggests a possible role for international agencies, particularly as higher education is given higher priority within international development agendas. The provision of external sup- 
port to explicitly fund sustained pedagogical training or establish new incentives that reward excellence in teaching could significantly increase the ability of public institutions to address academic quality concerns.

The results of this study indicate that, without sustained support for faculty development, it is likely that universities - in Rwanda, elsewhere in Africa, and beyond - will continue to struggle to implement the pedagogical changes necessary to foster critical thinking skills in their student populations. Institutions - and the governments and agencies that support themmust therefore acknowledge that faculty training and support is a crucial priority for international higher education reform.

\section{References}

Arum, Richard, and Josipa Roksa. 2011. Academically Adrift: Limited Learning on College Campuses. Chicago: University of Chicago Press.

Astin, Alexander W. 1970. "The Methodology of Research on College Impact." Pt. 1. Sociology of Education 43 (3): 223-54.

Astin, Alexander W. 1984. "Student Involvement: A Developmental Theory for Higher Education.” Journal of College Student Personnel 25 (4): 297-308.

Bailin, Sharon, Roland Case, Jerrold R. Coombs, and Leroi B. Daniels. 1999. "Common Misperceptions of Critical Thinking." Lournal of Curriculum Studies 31 (3): 269-83.

Barnett, Ronald, and SRHE (Society for Research into Higher Education). 1997. Higher Education: A Critical Business. Buckingham: SRHE \& Open University Press.

Baxter Magolda, Marcia B. 1999. Creating Contexts for Learning and Self-Authorship: Constructive-Developmental Pedagogy, ed. J. M. Braxton. Vanderbilt Issues in Higher Education. Nashville: Vanderbilt University Press.

Bell, James. 2005. Evaluating Psychological Information: Sharpening Your Critical Thinking Skills. Boston: Allyn \& Bacon.

Biggs, John. 2001. "Enhancing Learning: A Matter of Style or Approach?" In Perspectives on Thinking, Learning and Cognitive Styles, ed. R. J. Sternberg and L. F. Zhang. Mahwah, NJ: Erlbaum.

Blaich, Charles, and Kathy Wise. 2010. "Wabash National Study of Liberal Arts Education, 2006-2009: Overview of Findings from the First Year." Wabash College Center of Inquiry 2010. http:/ / www.liberalarts.wabash.edu/study-4th-year-data/.

Bok, Derek Curtis. 2006. Our Underachieving Colleges: A Candid Look at How Much Students Learn and Why They Should Be Learning More. Princeton, NJ: Princeton University Press.

Bransford, John D. 1979. Human Cognition: Learning, Understanding and Remembering. Belmont, CA: Wadsworth.

Braxton, John M., Deborah Olsen, and Ada Simmons. 1998. "Affinity Disciplines and the Use of Principles of Good Practice for Undergraduate Education." $\underline{R e}-$ search in Higher Education 39 (3): 299-318.

Carini, Robert M., G. D. Kuh, and Stephen Klein. 2006. "Student Engagement and Student Learning: Testing the Linkages." Research in Hioher Education 47 (1): 1-32. 
Cottrell, Stella. 2003. The Study Skills Handbook. 2nd ed. Basingstoke: Macmillan. Davies, W. Martin. 2006. “An 'Infusion' Approach to Critical Thinking: Moore on the Critical Thinking Debate." HioherEducation Research and Development 25 (2): 179-93. de Corte, Erik. 2000. "Marrying Theory Building and the Improvement of School Practice: A Permanent Challenge for Instructional Psychology." Learning and Instruction 10:249-66.

Dewey, John. 1933. How We Think: A Restatement of the Relation of Reflective Thinking to the Educative Process. Lexington, MA: Heath.

Dowling, Paul, and Andrew Brown. 2010. Doing Research/Reading Research: Reinterrogating Education. 2nd ed. London: Routledge.

Ennis, Robert H. 2009. "Investigating and Assessing Multiple-Choice Critical Thinking Tests." In Critical ThinkingEducation and Assessment: Can Higher Order Thinking Be Tested? ed. J. Sobocan and L. Groarke. London: Althouse.

Entwistle, Noel. 1997. "Contrasting Perspectives on Learning." In The Experience of Learning: Implications for Teaching and Studying in Higher Education, ed. F. Marton, D. Hounsell, and N. Entwistle. Edinburgh: Scottish Academic.

Entwistle, Noel, and Abigail Entwistle. 1997. "Revision and the Experience of Understanding." In The Experience of Learning: Implications for Teaching and Studying in HigherEducation, ed. F. Marton, D. Hounsell, and N. Entwistle. Edinburgh: Scottish Academic.

Green, Andy, and Akiko Sakamoto. 2001. "Models of High Skills in National Competition Strategies." In High Skills: Globalisation, Competitiveness, and Skill Formation, ed. P. Brown, A. Green, and H. Lauder. Oxford: Oxford University Press.

Guile, David. 2006. "What Is Distinctive about the Knowledge Economy? Implications for Education." In Education, Globalization, and Social Change, ed. H. Lauder, P. Brown, J.-A. Dillabough, and A. H. Halsey. Oxford: Oxford University Press.

Halpern, Diane F. 1996. Thought and Knowledge: An Introduction to Critical Thinking. 3rd ed. Mahwah, NJ: Erlbaum.

Kember, David, and Lyn Gow. 1994. "Orientations to Teaching and Their Effect on the Quality of Student Learning." Journal of Higher Education 65 (1): 58-74.

Kember, David, and Doris Y. P. Leung. 2005. "The Influence of the Teaching and Learning Environment on the Development of Generic Capabilities Needed for a Knowledge-Based Society." Learning Environments Research 8:245-66.

King, Patricia M., and Karen Strohm Kitchener. 1994. Developing Reflective Judgment: Understanding and Promoting Intellectual Growth and Critical Thinking in Adolescents and Adults. San Francisco: Jossey-Bass.

KIST Directorate of Planning and Development. 2007. "KIST Strategic Plan, 2007-10." Kigali: Kigali Institute of Science and Technology.

Kuh, G. D., and DEEP (Documenting Effective Educational Practice Project). 2005. Student Success in College: Creating Conditions That Matter. San Francisco: Jossey-Bass.

Kuhn, Deanna. 1995. "Microgenetic Study of Change: What Has It Told Us?" Psvchological Science 6:133-39.

Kuhn, Deanna. 1999. "A Developmental Model of Critical Thinking." Educational Researcher 28 (2): 16-25.

Kuhn, Deanna. 2005. Education for Thinking. Cambridge, MA: Harvard University Press.

Marshall, Catherine, and Gretchen B. Rossman. 2006. Designing Qualitative Research. 4th ed. Thousand Oaks, CA: Sage. 
Marton, F., and R. Saljo. 1976. "On Qualitative Differences in Learning." Pt. 1, "Outcome and Process." British Journal of Educational Psychology 46:4-11.

Mbabazi Bamwesiga, Penelope, Lars-Owe Dahlgren, and Andreas Fejes. 2012. "Students as Learners through the Eyes of Their Teachers in Rwandan Higher Education." International Journal of Lifelong Education 31 (4): 503-21.

Miles, Matthew B., and A. Michael Huberman. 1994. Qualitative Data Analysis: An Expanded Sourcebook. 2nd ed. Thousand Oaks, CA: Sage.

MINEDUC (Republic of Rwanda Ministry of Education). 2007. Rwandan National Qualifications Framework for Higher Education. Kigali: MINEDUC.

MINEDUC (Republic of Rwanda Ministry of Education). 2010. Education Sector Strategic Plan, 2010-2015. Kigali: MINEDUC.

Moon, Jennifer A. 2008. Critical Thinking: An Exploration of Theory and Practice. London: Routledge.

Moore, Tim. 2004. "The Critical Thinking Debate: How General Are General Thinking Skills?" Higher Education Research and Development 23 (1): 3-18.

Moore, Tim. 2011. "Critical Thinking and Disciplinary Thinking: A Continuing Debate." Hioher Education Research and Development 30 (3): 261-74.

Moseley, David. 2005. Frameworks for Thinking: A Handbook for Teaching and Learning. Cambridge: Cambridge University Press.

Pascarella, Ernest T., and Patrick T. Terenzini. 2005. How College Affects Students. 2nd ed. Jossey-Bass Higher Education Series. San Francisco: Jossey-Bass.

Phan, Huy P. 2011. "Deep Processing Strategies and Critical Thinking: Developmental Trajectories Using Latent Growth Analyses." Iournal of Educational Research 104 (4): 283-94.

Piaget, Jean. 1975. The Development of Thought: Equilibration of Cognitive Structures. Trans. A. Rosin. Oxford: Blackwell.

Republic of Rwanda MINECOFIN (Ministry of Finance and Economic Planning). 2000. Rwanda Vision 2020. Kigali: Republic of Rwanda.

Saavedra, Anna Rosefsky, and Juan Esteban Saavedra. 2011. "Do Colleges Cultivate Critical Thinking, Problem Solving, Writing and Interpersonal Skills?" Economics of Education Review 30:1516-26.

Salmi, Jamil, Adriaan M. Verspoor, and IAU (International Association of Universities). 1994. Revitalizing Higher Education: Issues in Higher Education. Oxford: Pergamon.

Schendel, Rebecca. 2013. "A Critical Missing Element: Critical Thinking at Rwanda's Public Universities and the Implications for Higher Education Reform." PhD diss., Institute of Education, London.

Schendel, Rebecca. 2015. "Critical Thinking at Rwanda's Public Universities: Emerging Evidence of a Crucial Development Priority." International Journal of Educational Development 42:96-105.

Schendel, Rebecca, and Andrew Tolmie. 2016. "Beyond Translation: Adapting a Performance-Task-Based Assessment of Critical Thinking Ability for Use in Rwanda." Assessment and Evaluation in Higher Education. doi:10.1080/02602938 .2016 .1177484 .

Star, Cassandra, and Sara Hammer. 2008. "Teaching Generic Skills: Eroding the Higher Purpose of Universities, or an Opportunity for Renewal?" Oxford Review of Education 34 (2): 237-51. 
Stark, Joan S., M. A. Lowther, R. J. Bentley, M. P. Ryan, M. L. Genthon, G. G. Martens, and P. A. Wren. 1990. Planning Introductory College Courses: Influences on Faculty. Ann Arbor: University of Michigan Press.

Tabulawa, Richard. 2013. Teaching and Learning in Context: Why Pedagogical Reforms Fail in Sub-Saharan Africa. Dakar: CODESRIA.

Tikly, Leon, and DFID (Great Britain Department for International Development). 2003. Globalisation and Skills for Development in Rwanda and Tanzania. Education Research 51. London: DFID.

Tsui, Lisa. 2001. "Faculty Attitudes and the Development of Students' Critical Thinking." Iournal of General Education 50 (1): 1-28.

Tsui, Lisa. 2002. "Fostering Critical Thinking through Effective Pedagogy: Evidence from Four Institutional Case Studies." Lournal of Higher Education 73 (6): 740-63.

UNESCO. 2009. Final Report: World Conference on Higher Education. Paris: UNESCO.

Vygotsky, L. S., Michael Cole, and A. R. Luria. 1978. Mind in Society: The Development of Higher Psychological Processes. Cambridge, MA: Harvard University Press.

World Bank. 2009. Accelerating Catch-Up: Tertiary Education for Growth in Sub-Saharan Africa. Directions in Development: Human Development. Washington, DC: World Bank.

Yin, Robert K. 2009. Case Study Research: Design and Methods. 4th ed. London: Sage. 